\title{
The Instructional Capacity of Reality Television: Learning Survival Strategies from Survival Shows
}

\author{
By Kami Kosenko* \\ Johanne Laboy ${ }^{\dagger}$ \\ Danielle Schmidt
}

\begin{abstract}
One of the broadcast industry's early forays into reality television, Rescue 911, was credited with teaching viewers life-saving techniques; however, this notion was never empirically tested. A new spate of reality shows, such as I Survived..., presents another opportunity to assess the teaching potential of these programs. To this end, this study, guided by social learning theory, explored whether media exposure influenced the type or number of survival strategies that individuals intended to use in a life-threatening situation. We conducted two experiments in which participants were randomly assigned to view a video of an individual describing his or her escape from a perilous situation and then asked what they would do to survive a similar threat. In comparison to participants who did not view the videos, viewers were more likely to mention using survival strategies depicted in the show, thus supporting assertions about the instructional capacity of some reality shows.
\end{abstract}

Keywords: experimental design, reality television, social learning, survival strategies, violence

\section{Introduction}

The proliferation of reality television programs is often traced to the $1980 \mathrm{~s}$ when a financial crunch and a five-month writers' strike forced the networks to invest in cheaper, unscripted fare. Born out of the broadcast industry's financial crisis were shows such as America's Most Wanted, Unsolved Mysteries, America's Funniest Home Videos, and Rescue 911 (Murray, 2004). Rescue 911, which debuted in 1988 and featured re-enactments of near disasters narrowly averted by calls to 911, quickly became one of the highest-rated television programs of the time (Hinton, 1999). Hosted by William Shatner, whose past roles as Captain Kirk and TJ Hooker afforded him a degree of authority and credibility with audiences, Rescue 911 became an international hit, airing in 45 foreign countries and spawning copycat programs, such as the BBC's 999 (Brooks \& Marsh, 2007; Hill, 2005). Although the program also went on to win a People's Choice Award, its producer/creator, Arnold Shapiro, took the most pride in an unintended consequence of the show-its viewers were learning how to prevent tragedies and save lives (personal communication, March 7, 2012). Numerous calls and letters from viewers describing lives changed and saved by watching Rescue 911 led to two special episodes of the show, aptly titled "100 Lives Saved" and "200 Lives Saved", that featured the stories of those who had learned and

\footnotetext{
*Associate Professor of Communication, North Carolina State University, USA. ${ }^{\dagger} \mathrm{PhD}$, Department of Communication, North Carolina State University, USA.

${ }^{\ddagger}$ Master Student, Department of Communication, North Carolina State University, USA.
} 
applied the life-saving techniques depicted in the program (Hinton, 1999). Despite this anecdotal evidence of Rescue 911's effects on viewers, the potential for the show, or any media content, to teach viewers survival strategies has not been explored empirically.

A new spate of reality television programs presents another opportunity to explore the teaching potential of shows like Rescue 911. For example, CBS's Survivor, NBC's Get Out Alive, Discovery Channel's Naked and Afraid, and Biography Channel's I Survived... all feature real people and their efforts to survive extreme circumstances. Although the hardships faced by those on Survivor, Get Out Alive, and Naked and Afraid are orchestrated by producers, I Survived... is unique in that it centers on individuals who have lived through extraordinary events, such as natural disasters, animal attacks, and violent crimes (Kosenko \& Laboy, 2014). Despite the differences between these survival shows and the artifice inherent in some (if not all) "reality" television, viewers of these programs, like those who watched and learned from Rescue 911, could be acquiring survival skills by observing the experiences of the people on these shows. This study was designed to test this basic hypothesis.

Although the notion that television programs might teach life-saving survival skills might be novel, the idea that viewers can learn from watching television is far from new. In fact, one of the largest and most storied lines of research in mass communication explores the potential for violent media content to teach and elicit anti-social and aggressive behavior in its viewers (for a review, see Potter, 1999). A smaller but complementary body of work addresses the educational functions of children's shows, such as Sesame Street and Blues Clues, and the kinds of prosocial behaviors that children learn from watching these programs (Bryant \& Thompson, 2002). When studying these types of media effects, researchers typically turn to Albert Bandura's (1976) social learning theory, which provides a fitting lens through which to view the present investigation.

Social learning theory explores the determinants of human behavior and the mechanisms by which we learn (Bryant \& Thompson, 2002). Bandura (2001) believes that we all possess a degree of personal agency but that our actions are embedded within and, thus, shaped by social structures. As such, he assumes that human action is dictated by the reciprocal influences of personal experiences and characteristics and environmental factors - a concept he calls triadic reciprocal causation. Although Bandura asserts that society is fashioned by the self (and vice versa), his views on environmental influences on learning and behavior are more relevant to the present investigation and, thus, warrant further discussion.

According to the theory, we learn through personal and vicarious experiences with the environment and the consequences of those environmental transactions (Bandura, 2001). For example, by touching and being burnt by an open flame, we learn that fire is hot and should not be touched. Although Bandura acknowledged that personal experience provided particularly powerful behavioral incentives and disincentives, he realized that social structures and environmental constraints limited the extent to which one could learn from direct experience, alone. As he explained, "The constraints of time, resources, and mobility impose severe limits on the places and activities that can be directly explored for the acquisition 
of new knowledge and competencies" (p. 270). Given these constraints, Bandura's theory placed considerable emphasis on the importance of observational learning.

Bandura (2009) reasoned that virtually everything one could learn by doing could be also be learned by observing the actions of others and the consequences of those actions - a process he called observational learning. According to the theory, the "other" serves as a behavioral model for the "self", sparing the self the tedious task of acquiring all new knowledge and skills through direct experience and processes of trial-and-error. Although Bandura believed that most of these models were part of one's immediate environment, he also recognized that the symbolic environment of the mass media held great modeling potential. In fact, he argued that, "Because of the symbolic environment occupies a major part of people's everyday lives, much of the social construction of reality and shaping of public consciousness occurs through electronic acculturation" (p. 98).

Despite the emphasis Bandura (2009) placed on observational learning, he acknowledged that individuals did not learn from or imitate every behavior they observed. Instead, he argued that four subfunctions of the observational learning process-attention, retention, performance, and motivation-dictated the acquisition and execution of a modeled skill or behavior. In short, an individual must attend to a behavioral model, retain the modeled behavior, translate this cognition into behavior, and be sufficiently motivated to engage in this process if he or she is to perform an observationally learned behavior. Applications of Bandura's theory with both real-life and mediated models helped researchers identify other factors that influenced these subfunctions, including identification with the model, the perceived realism of the observed behavior, and the punishments and rewards associated with the model's actions. For example, identification with the model, which is enhanced by his or her attractiveness, credibility, and/or perceived similarity, is thought to influence attention to the modeled behavior, the first subfunction of the observational learning process (Pajares, Prestin, Chen, \& Nabi, 2009). Attention to and retention of observed actions also are affected by perceived realism such that realistic portrayals are more likely to result in imitation than fantastical depictions (Tukachinsky, 2013). Finally, punishment and reinforcement of the observed behavior affect one's motivations to emulate the model. In effect, people are motivated to perform behaviors seen as successful or rewarding but discouraged from imitating models who are punished for their actions (Bandura, 2009).

Although widely cited and generally accepted by mass communication scholars, these assumptions of social learning theory have been subject to surprisingly few empirical tests (Nabi \& Clark, 2008). In fact, a search of databases, such as Communication and Mass Media Complete, Psychinfo, and Academic Search Complete, yields far more content analytic work that uses the theory as justification for examining particular types of media content than experimental studies that are guided by or designed to test the theory's tenets. Moreover, of the work that has used the theory to study media effects (as opposed to media content), the vast majority focuses on anti- and pro-social behavioral effects (Perse, 2007), ignoring the wide variety of skills and behaviors that one can learn from the symbolic environment of the mass media (Sparks, 2013). 
Learned behaviors that are more neutral or mundane, such as the cooking techniques taught on the Food Network or the home improvement strategies suggested by the design experts on HGTV, are given short shrift in comparison to the potentially violence-inducing content of primetime television and the educational elements of children's programming (Brannigan, 2004). Finally, despite distinctions made between the effects of realistic and unrealistic media portrayals, studies that have employed manipulated media content to test the theory and its assumptions have relied almost exclusively on fictional programs (Nabi \& Thomas, 2013).

The present study serves as a preliminary attempt to address these limitations. To ascertain the instructional capacity of reality tv and to determine if individuals can attend to and retain more than just anti- and prosocial behaviors from the media, we designed an experiment in which participants who did and did not view a survival reality program were asked to describe what they would do to survive an extreme event. To increase our confidence in our findings as well as their generalizability, we conducted the same experiment twice, varying the videos to which participants were exposed and the extreme event under consideration. We undertook each experiment to address the following research question: Does viewing a reality show featuring a person describing his or her survival techniques influence the type and/or number of strategies one intends to use in a similar situation?

\section{Method}

We employed an experimental design to determine if individuals' intentions to use a specific type or number of strategies in order to survive a life-threatening event were affected by the media. We conducted two experiments in which participants were randomly assigned to one of two conditions (for a total of four conditions across the two experiments). In each experiment, participants in the first condition read a written description of a hypothetical, life-or-death situation and were asked to describe, in detail, what they would do to survive. Instead of reading a written description of the scenario, participants in the second condition watched a brief video in which a person described the scenario and the steps he or she took to survive. The participants in condition two were then asked to detail how they would respond if they found themselves in the same situation described in the video. We conducted this experiment twice, using two different sets of participants and varying the life-or-death event (and the video depicting it). In the first experiment, condition one involved a written description of a bear attack, and condition two involved a video of a man who described how he fought off a bear in the woods. In the second experiment, condition one entailed a written description of interpersonal violence, and, in condition two, participants viewed a video of a woman recounting how she survived a violent attack by her ex-boyfriend. All participants' open-ended descriptions of what they would do in a similar situation were coded to identify their intended survival strategies, and we looked for statistical differences 
between the two groups (in each experiment) in terms of the type and number of strategies described. The following sections describe the sample, procedures, and stimuli in further detail.

\section{Sample}

Participants were recruited from Communication courses at a large, public University in the southern United States. The authors announced the study in these courses, and course instructors offered extra credit to those who participated. One hundred twenty-nine students took part in the first experiment, and 126 individuals completed the second experiment. The sample for the first experiment was comprised of 79 females (61.2\%) and 50 males (38.8\%) with an average age of 20.9 years (range $=18-53$ years). Eighty-nine participants $(69.0 \%)$ selfidentified as non-Hispanic white, $21(16.3 \%)$ as African-American, $12(9.3 \%)$ as Asian, $6(4.7 \%)$ as Latina/Latino, and one participant $(0.8 \%)$ identified as biracial. Forty-three males $(34.1 \%)$ and 83 females $(65.9 \%)$ with an average age of 20.0 years (range $=18-35$ years) took part in the second experiment. Ninety-two participants $(73.0 \%)$ in the second experiment identified as nonHispanic white, $12(9.5 \%)$ as Asian, $11(8.7 \%)$ as African American, 2 (1.6\%) as Native American, and $2(1.6 \%)$ as biracial.

\section{Procedures}

The following procedures were approved by our Institutional Review Board. Recruitment materials for this study described its purpose (i.e., to ascertain individuals' television viewing practices and their reactions to specific kinds of media content), listed inclusion/exclusion criteria (i.e., individuals age 18 or over with computer and Internet access), and provided a URL for a website that included an online questionnaire. Interested and qualified parties were directed to visit the website and complete the linked questionnaire. The questionnaire, created and hosted on Qualtrics.com, began with a consent form, which participants were encouraged to print for their records. After completing a series of demographic questions and responding to inquiries about their television viewing practices, participants were randomly assigned to one of two conditions. In both experiments, condition one involved a written description of a hypothetical lifethreatening situation, which was followed by the question, "What would you do in this situation?". Participants in the second condition in each experiment viewed a video, which featured a person describing a life-threatening situation and the strategies that he or she used to survive. In experiment one, participants responded to the following hypothetical: "Imagine that you are alone in the woods and you encounter a bear. If the bear attacks, what would you do?". The video condition for experiment one featured a man describing his experience fighting a bear in the woods. After viewing the video, participants in this condition were asked to describe what they would do in that situation. For experiment two, the following hypothetical was posed: "Imagine that you are on a date with someone who becomes enraged and threatens you with a razor blade. Your date is driving you 
out to a deserted area where you fear he/she might hurt you. What would you do?". The video for experiment two showed a woman in this situation and the steps she took to survive. The video was followed by the question, "What would you do in this situation?". In experiment one (i.e., the bear attack), 67 participants saw the written description, and 62 individuals viewed the video. In experiment two (i.e., the human attack), 58 participants watched the video, and 68 read the written description of the attack.

Participants' open-ended responses to the "what would you do?" questions were used to generate a list of survival strategies, which formed the basis for a coding scheme. Because participants described different strategies in response to the animal and human attacks, we created two coding schemes-one for each experiment. Each coding scheme was designed to be exhaustive, and the codes were meant to be mutually exclusive. From participant responses to the animal attack scenario, we identified 13 different survival strategies. These included getting distance from the bear, trying to confuse or distract the animal, hiding, protecting one's vital parts, fighting, playing dead, asserting dominance, seeking help, giving up, staying still, exerting self-control, doing whatever it takes to survive, and doing the same as the person featured in the video. In response to the human attack scenario, participants described 12 possible responses. To survive a violent encounter with a date, participants said that they would try to manipulate their attacker, make an offensive maneuver, seek help from others, jump out of the moving vehicle, run away from the vehicle and perpetrator, stay calm, keep track of and leave clues for apprehension and prosecution of the attacker, pray, cooperate with the attacker, play dead, summon the will to survive, and do the same as the person did in the video.

Once the survival strategies were identified and the coding schemes were developed, we were able to conduct a quantitative content analysis of participant responses from each experiment. To ascertain intercoder reliability, we randomly selected twenty responses from each condition (for a total of 40 responses per experiment) and had two trained coders determine which codes (i.e., survival strategies) were present in each response. The study authors calculated Krippendorff's alpha for each of the 25 codes and determined that inter-coder reliability was sufficiently high (i.e., all reliabilities were greater than 0.86 ) to warrant splitting the rest of the coding between the two coders. Once all participant responses were coded, we calculated the total number of strategies described by each participant and used Chi-square and t-tests to examine if the type and number of strategies mentioned differed between the two conditions.

\section{Stimuli}

We derived the video stimuli for the two experiments from the reality television series, I Survived... . The hour-long show, which, after its debut in 2008, became the Biography Channel's highest rated program, features interviews with two to four survivors of life-threatening events. For the program, the interviews have been edited to 20-25 minutes in length and to show only the survivor (and not the interviewer). Each survivor recounts what occurred prior 
to, during, and after the event that threatened his or her life and tells, in detail, the steps he or she took to survive. Although some survivors describe events such as natural disasters and workplace accidents, most interviewees recall situations in which their lives were threatened by violence or animal attacks. As such, we chose two interviews to use as our video stimuli-one featuring an animal attack survivor and the other focusing on interpersonal violence.

In the animal attack video, Brent told his story, which involved being alone in the woods and suddenly attacked by a bear. Brent described using three main survival strategies during the attack: protecting his vital parts, playing dead, and doing whatever it took to survive. Although he suffered deep lacerations to his arms and shoulders and was nearly scalped by the bear, he avoided further injury by protecting his neck and chest and fooling the bear into thinking he was dead. Brent ended the interview by attributing his survival to doing whatever it took to survive. The human attack video featured Sharene who narrowly escaped being killed by a violent, cocaine-fueled ex-boyfriend who drove her to a deserted area and threatened her with a razor blade. Sharene attributed her survival to three strategies: leaping from the moving vehicle, getting distance from her attacker, and playing dead. After having her throat slashed by her ex-boyfriend, Sharene decided to jump out of the car and try to run away, but her attacker soon caught up with her and began stabbing her with a pair of scissors. As Sharene recalled, "I knew that the only way that I could maybe possibly survive was to play dead. So, I played dead". Sharene was then able to get away from her attacker and to live to tell her tale. Although study participants said that they would employ various strategies if faced with situations similar to those endured by Brent and Sharene, we focused our analysis on the tactics described in the video. As such, we sought to determine if those exposed to the videos were more likely to mention using the same strategies as Brent (i.e., protecting vital parts, playing dead, and doing whatever it took to survive) and Sharene (i.e., leaping from the car, getting distance from the attacker, and playing dead) than those who did not watch the videos.

\section{Results}

Each experiment was designed to determine if exposure to survival programming influenced the type and/or number of survival strategies that individuals intended to use in a similar, life-threatening situation. In the first experiment, one group of participants watched a video of a man describing how he survived a bear attack by protecting his vital parts, playing dead, and doing whatever it took to survive. Their responses to the question, "what would you do in this situation?", were compared to those produced by a second group of participants who did not watch the video but were asked to imagine how they would respond to having their lives threatened by a bear. To determine if exposure to the video influenced the type of strategies reported by participants, we used Chi-square tests and examined whether the groups differed in terms of the frequency with which they mentioned protecting their vital parts, playing 
dead, and doing whatever it took to survive. Although mentions of protecting one's vital parts did not differ significantly between the two groups $\left[\chi^{2}(1)=0.03\right.$; $p=0.53$ ], significant differences emerged in terms of the other two strategies used by Brent. Those who watched the video were more likely to mention playing dead $\left[\chi^{2}(1)=14.40 ; p=0.00\right]$ and doing whatever it took to survive $\left[\chi^{2}(1)=8.00\right.$; $p=0.005]$ than those who did not see Brent's story. A $t$-test revealed that those who watched the video also referenced significantly more survival strategies than those in the non-video condition, $t(127)=-2.54 ; p=0.01$.

For the second experiment, we changed the video stimulus and the lifethreatening situation. In this experiment, one group of participants viewed Sharene's story about being threatened by an ex-boyfriend with a razor blade and a pair of scissors while a second group responded to a written description of Sharene's experience. The two groups' responses to the question, "what would you do in this situation", were compared to see if those who watched the video were more likely to report using the same strategies as Sharene-leaping from the vehicle, getting distance from the attacker, and playing dead. The two groups did not differ significantly in terms of their references to leaping from the vehicle $\left[\chi^{2}(1)=0.79 ; p=0.25\right]$; however, those in the video condition were significantly more likely to mention getting distance from the attacker $\left[\chi^{2}(1)=10.35 ; p=0.001\right]$ and playing dead $\left[\chi^{2}(1)=7.39 ; p=0.008\right]$ than those who did not view the video. There were no significant differences $[t(124)=1.27$; $p=0.21$ ] between the groups in terms of the total number of strategies mentioned.

\section{Discussion and Conclusion}

The results of this study indicate that viewers may learn survival strategies from the reality show, I Survived... . We conducted two experiments to determine if watching the show influenced the type or number of survival strategies that individuals intended to use in life-threatening situations, and, in each experiment, viewers were more likely than non-viewers to mention using four of the six tactics depicted in the program. Findings were mixed, however, with respect to the number of strategies employed. In the first experiment, which involved a hypothetical bear attack, viewers mentioned significantly more strategies than non-viewers; whereas, the human attack scenario (i.e., experiment two) yielded no significant differences in the number of strategies reported. These findings as well as their implications for theory and research warrant further consideration.

The survivors shown in each video described using three strategies to escape their attackers. When asked what they would do to survive, participants who viewed these videos were more likely to mention two of the three strategies than those who did not view the program. In addition, half of those who watched the animal attack video and 53\% of participants who saw Sharene's story indicated that they would do the same things depicted in the videos. These findings provide empirical support for claims made about the instructional potential of survival shows, such as I Survived..., and extend the work done by Cantor and colleagues on "teachable moments" in the media. Wondering if there is a "silver lining" to 
the dark cloud that is violent media content, Cantor and Omdahl (1999) conducted a series of experiments to determine if viewing media representations of a threatening event made children more receptive to learning related safety guidelines. Although they did not assess learning, per se, they did find that exposure to a dramatized accident followed by a description of steps used to prevent said accident influenced children's beliefs about the importance of following safety guidelines. The next step, they reasoned, was "to determine whether children actually learn safety information when it is presented in a fear-arousing context" (p. 68). The present investigation indicates that adults attend to and retain safety and survival information presented in television programs. Further tests are needed to replicate this experiment and to determine if younger audiences respond to survival stories in the same manner.

The idea that one can learn how to survive life-threatening events from watching media depictions of those events should come as no surprise to anyone who has ever watched a horror movie and criticized the protagonist's ill-conceived efforts to evade his or her attacker. For many of us, watching others in peril prompts us to think about how we would respond in a similar, perilous situation. Although many of us may be more likely to respond to a violent movie by yelling, "don't run up the stairs", or, "check that he's really dead", than by committing an act of violence, we have focused more of our time and energy on the latter response than the former. Findings from this study suggest that media violence might prompt more than just aggression in its viewers; violent media content might teach viewers the skills necessary to survive said acts of violence. Although researchers have examined the positive attitudes and behaviors taught by media programs, such as Blue's Clues and Sesame Street (e.g., Anderson et al., 2000; Fisch, Truglio, \& Cole, 1999), scholars have yet to explore the beneficial behaviors that one might learn from violent media content. This study serves as a first step in this direction, but continued study of media violence and its potentially positive effects on media consumers is necessary.

Although social learning theory offers a compelling explanation for the results of the present investigation, other theories, such as media priming, could account for these findings. Priming occurs when stimuli, such as media content, "activates" related cognitions. Although priming effects dissipate quickly, "for a certain period of time after viewing, a person is more likely to have thoughts about the content, related thoughts, or memories than a person who does not view the content" (Bryant, Thompson, \& Finklea, 2013, p. 86). Given the short length of time between exposure to the I Survived... videos and the completion of the experimental task, participant responses could have been primed (as opposed to learned). Priming also might explain why we saw effects for only two of the three strategies depicted in each video. In each video, one strategy (i.e., the non-significant finding) was mentioned near the beginning and the other two (i.e., the significant findings) were brought up closer to the end. These recency effects make sense in light of priming research demonstrating that proximal content produces the most powerful primes (Dodge, Coie, \& Lynam, 2006). Given the applicability and utility of priming theory to this line of research, future 
work in this area should consider adopting this perspective in lieu of or in addition to a social learning framework.

Future work also should attempt to address the limitations of this study. First, discrepancies between the written and video conditions (i.e., the video conditions included descriptions of survival strategies, whereas the written descriptions did not) created the potential external validity threats, which will need to be addressed in future studies employing a similar design. Second, like most research guided by social learning theory, this study only addresses behavioral intentions. Although designing a study that threatens a participant's life and, thus, elicits a real survival response would be unethical and inhumane, studying media effects on actual behavior would provide the only true test of social learning theory and its tenets (Glassman \& Hadad, 2009). Moreover, longitudinal tests are needed to determine if the effects seen here are driven by social learning or priming (Anderson \& Huesmann, 2003). Data concerning the retention of the strategies depicted in the show and long-term behavioral maintenance would bolster our claims about the teaching potential of I Survived... and other survival programs.

Despite these limitations, this study provides preliminary evidence of the instructional capacity of reality television. Although often bemoaned as trash tv, reality television shows, such as I Survived..., seem to have some redeeming qualities. This study underscores the importance of considering these qualities and other potential positive effects of media consumption.

\section{References}

Anderson, D. R., Bryant, J., Wilder, A., Santomero, A., Williams, M., \& Crawley, A. M. (2000). Researching Blue's Clues: Viewing behavior and impact. Media Psychology, 2, 179-194.

Anderson, C. A., \& Huesmann, L. R. (2003). Human aggression: A social-cognitive view. In M. A. Hogg \& J. Cooper (Eds.), The handbook of social psychology (pp. 296-323). Thousand Oaks, CA: SAGE.

Bandura, A. (1976). Social learning theory. New York, NY: Prentice-Hall.

Bandura, A. (2001). Social cognitive theory of mass communication. Media Psychology, $3,265-299$.

Bandura, A. (2009). Social cognitive theory of mass communication. In J. Bryant \& M. B. Oliver (Eds.), Media effects: Advances in theory and research (3rd ed., pp. 94-124). New York, NY: Routledge.

Brannigan, A. (2004). The rise and fall of social psychology: The use and misuse of the experimental method. New York, NY: Walter de Gruyter.

Brooks, T., \& Marsh, E. (2007). The complete directory to prime time network and cable tv shows, 1946-present. New York, NY: Ballantine.

Bryant, J., \& Thompson, S. (2002). Fundamentals of media effects. New York, NY: McGraw-Hill.

Bryant, J., Thompson, S., \& Finklea, B. W. (2013). Fundamentals of media effects (2nd ed.). Long Grove, IL: Waveland Press. 
Cantor, J., \& Omdahl, B. (1999). Children's acceptance of safety guidelines after exposure to televised dramas depicting accidents. Western Journal of Communication, 63, 57-71.

Dodge, K. A., Coie, J. D., \& Lynam, D. (2006). Aggression and antisocial behavior in youth. In N. Eisenberg (Ed.), Handbook of child psychology, vol. 3: Social, emotional, and personality development (pp. 719-788). Hoboken, NJ: John Wiley \& Sons.

Fisch, S. M., Truglio, R. T., \& Cole, C. F. (1999). The impact of Sesame Street: A review and synthesis of 30 years' research. Media Psychology, 1, 165-190.

Glassman, W., \& Hadad, M. (2009). Approaches to psychology (5th ed.). Maidenhead, Berkshire: Open University Press.

Hill, A. (2005). Reality TV: Audiences and popular factual television. New York, NY: Routledge.

Hinton, L. (1999). The perverse gaze of sympathy: Sadomasochistic sentiments from Clarissa to Rescue 911. Albany, NY: State University of New York Press.

Kosenko, K., \& Laboy, J. (2014). "I Survived": The Content and Forms of Survival Narratives. Journal of Loss and Trauma, 19(6), 497-513.

Murray, S. (2004). Reality television. In H. Newcomb (Eds.), Encyclopedia of television (pp. 1900-1902). New York, NY: Routledge.

Nabi, R. L., \& Clark, S. (2008). Exploring the limits of social cognitive theory: Why negatively reinforced behaviors on tv may be modeled anyway. Journal of Communication, 58, 407-427.

Nabi, R. L., \& Thomas, J. (2013). The effects of reality-based television programming on diet and exercise motivation and self-efficacy in young adults. Health Communication, 28, 699-708.

Pajares, F., Prestin, A., Chen, J., \& Nabi, R. L. (2009). Social cognitive theory and media effects. In R. L. Nabi \& M. B. Oliver (Eds.), The SAGE handbook of media processes and effects (pp. 283-298). Thousand Oaks, CA: SAGE.

Perse, E. (2007). Meta-analysis: Demonstrating the power of mass communication. In R. W. Preiss (Eds.), Mass media effects research: Advances through meta-analysis (pp. 467-488). New York, NY: Routledge.

Potter, W. J. (1999). On media violence. Thousand Oaks, CA: SAGE.

Sparks, G. G. (2013). Media effects research: A basic overview. Boston, MA: Wadsworth.

Tukachinsky, R. (2013). Realism of violent content, real-world violence on television, and its effects. In M. S. Eastin (Ed.), Encyclopedia of media violence (pp. 31318). Thousand Oaks, CA: SAGE. 
